\title{
Optimization Call Detail Record in Oracle Communication Monitoring System - Performance Intelligence Center (OC - PIC) on SS7 International SMS Network
}

\author{
Aji Bagus Pambudi ${ }^{1}$, Muhammad Hanif Ramadhan ${ }^{2}$, Daniel Patricko Gemeno Hutabarat ${ }^{3}$ \\ ${ }^{1}$ Computer Engineering Department, Faculty of Engineering, Bina Nusantara University, Jakarta, Indonesia \\ 11480 \\ ${ }^{2}$ Computer Engineering Department, Faculty of Engineering, Bina Nusantara University, Jakarta, Indonesia \\ 11480 \\ ${ }^{3}$ Computer Engineering Department, Faculty of Engineering, Bina Nusantara University, Jakarta, Indonesia \\ 11480, danielhbarat@binus.ac.id
}

\begin{abstract}
Introduce a dynamic categorization for clustering and searching task by SS7 basics, ISUP call flow, SCCP(MAP) transaction and Eagle STPasaSS7router.Research method were conducted by problem identification and domonitoring SS7 using monitoring tools OC-PIC integration from Signal Transfer Point(STP) to do tracingSS7 call and SMS transaction. OC-PIC (Oracle Communications Performance Intelligence Center) perform as database application whichisSTPintegrationtotakedataafteridentificationtheproble $m$.The result of this thesis was that can optimize configuration so that can be easier to solve the problem and avoid transaction data that is separated especially in SMS.It can be concluded configuration can reduce not appropriate transaction data.
\end{abstract}

Key words: ISUP, SCCP(MAP), SS7,STP

\section{INTRODUCTION}

Telecommunication systems have emerged throughout the world and it is considered as the most widely used technology. [1].Short message service or short term (English: Short Message Service abbreviated as SMS) is a service carried out with a cell phone to send or receive short messages. At first SMS was designed as part of GSM, but now it has gotten on mobile networks including UMTS networks.

A maximum SMS message consists of 140 bytes, in other words it can load 140 8-bit characters, 1607 -bit characters or 70 16-bit characters [2]. In addition to 140 bytes, there are other data included. There are also several methods for sending messages that are more than 140 bytes, but users have to pay more than once [3]. Short Message Service SMS can also send pictures and sounds. This form of SMS is called MMS. SMS messages are sent from a mobile phone to the message center (SMSC in English), here the message is saved and tries to send it several times[4]. After a predetermined time, it is usually 1 day or 2 days, then the message is deleted. A user can get confirmation from this message center.

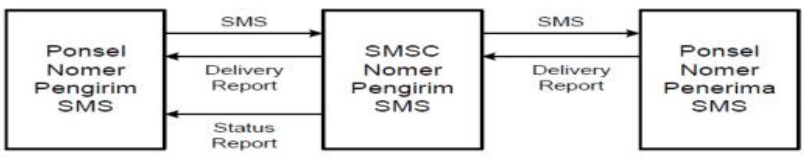

Figure 1:Intra-Operator SMS Mechanism (Design of Broadcasting Systems Using Multiple GSM Modem, 2010)

The SMS sent by the number of the sender will be entered first into the SMSC of the sender's number operator, then the SMSC will send it to the number directly addressed.

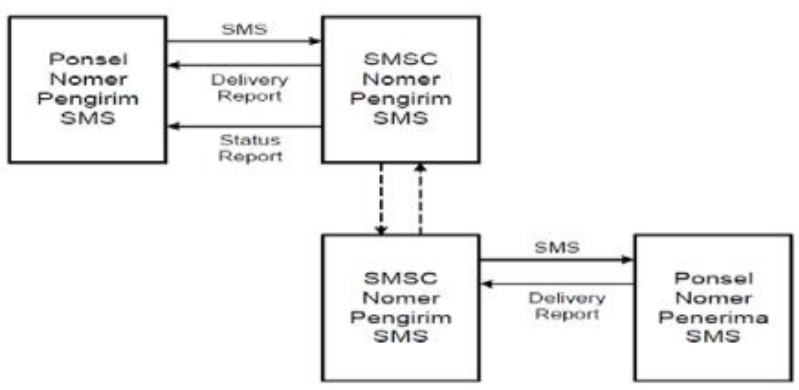

Figure 2:SMS Inter-Operator Mechanism (Design of Broadcasting Systems Using Multiple GSM Modem, 2010)

In addition to entering the SMSC operator, the SMS sent will be forwarded by the sending operator's SMSC to the SMS 
Aji Bagus Pambudi et al., International Journal of Emerging Trends in Engineering Research, 8(9), September 2020, $5832-5837$

recipient operator's SMSC, then forwarded to the destination number.

Basically, the SMS traffic that passes through the SMSC device is very much. Recorded in 2017, the number of messages sent via SMS reached 20 billion per day.

Based on the data mentioned earlier, it would be very difficult if someone would monitor or monitor the SMSC device. Therefore, one can use an application or software to make it easier to monitor traffic.

To carry out their daily tasks safely and make the right decisions, it is necessary to thoroughly monitor their core network (Core Network), with flexible tools that provide visibility and enable smooth transition from $3 \mathrm{G} / 2 \mathrm{G}$ to LTE services. (Oracle Communication Performance Intelligence Center 10.2 Feature Guide, 2016)

The author focuses on analyzing lanes of SMS roaming transaction traffic that are owned by state-owned or stateowned providers. Basically the transactions here are divided into two, namely based on MSU and transactions per SMS for billing calculations between overseas and domestic providers.

The problem that we will raise is regarding monitoring data, where MSU from the SMS transaction is incomplete, because it is not grouped with the MSU partner so that the SMS with MSU that is incomplete will be read that the SMS has a Timer status (does not get MSU reciprocity with End status) or status of Not Matched (Does not have MSU BEGIN).

\begin{tabular}{|c|c|c|c|c|c|c|c|}
\hline Period end & Link & Total & DR_OK & DR_ Timer & RatiooK & RatioNoilMatched & RalioTimer \\
\hline . & . & 526459 & 152588 & 121107 & $28,98 \%$ & $37,45 \%$ & $23,00 \%$ \\
\hline 19:07/2017 11:20:00 & sb1p-trlotbsm2-0 & 33281 & 12076 & 7335 & $36,28 \%$ & $24,38 \%$ & $22,03 \%$ \\
\hline 19:07:2017 11:20:00 & sb1p-tlrotbsm2-1 & 33583 & 12371 & 7296 & $36,83 \%$ & $26,67 \%$ & $21,72 \%$ \\
\hline 19:07/2017 11:20:00 & $\mathrm{j} k 1 p-\mathrm{tr} \mathbf{r}$ tbsm2-0 & 31316 & 10762 & 5076 & $34,36 \%$ & $39,54 \%$ & $16,20 \%$ \\
\hline 19:07/2017 11:20:00 & jk1p-trobrnm 2-1 & 21195 & 5257 & 4744 & $24,80 \%$ & $39,86 \%$ & $22,38 \%$ \\
\hline 19:07/2017 11:20:00 & jkip-trotosmm2-1 & 23903 & 7110 & 4653 & $29,74 \%$ & $39,04 \%$ & $19,46 \%$ \\
\hline 19:07/2017 11:20:00 & sb1p-trobrnm 2-1 & 21615 & 6223 & 4642 & $28,79 \%$ & $42,55 \%$ & $21,47 \%$ \\
\hline 19:07/2017 11:20:00 & jkip-trobrnm 2-0 & 19445 & 4555 & 4546 & $23,42 \%$ & $44,56 \%$ & $23,37 \%$ \\
\hline 19:07/2017 11:20:00 & sb1 p-ttrobrmm2-0 & 17491 & 4252 & 4205 & $24,30 \%$ & $43,75 \%$ & $24,04 \%$ \\
\hline $9: 072017 \div 11.20: 00$ & Kiptictithkg-0 & 9288 & 413 & 3057 & $4,44 \%$ & $61.69 \%$ & $3290 \%$ \\
\hline 19:07/2017 11:20:00 & sb1p-tilttamonc-1 & 7907 & 1253 & 2997 & $15,84 \%$ & $42,00 \%$ & $37,90 \%$ \\
\hline 19:07/2017 11:20:00 & sb1p-tittatatrc-0 & 8268 & 1313 & 2890 & $15,88 \%$ & $44,79 \%$ & $34,95 \%$ \\
\hline 19:07/2017 11:20:00 & sb1p-tittamonc-0 0 & 6965 & 1154 & 2651 & $16,56 \%$ & $41,24 \%$ & $38,06 \%$ \\
\hline KET: & & & & & & & \\
\hline & $\begin{array}{l}\text { : data sampel yang o } \\
\text { ambil }\end{array}$ & & & & & & \\
\hline
\end{tabular}

Figure 3: Data Ratio of SMS Transactions at Specified Times (Source processed, 2018)

When viewed in Figure 3, the ratio of Not Matched status tends to be high. For the company, the figure is certainly not the good number, because the validity of the data or the validity of a data will impact later on to do the billing process and to Troubleshooting a problem in a communication network.

The main objective of the author is to optimize the ratio from the status of Not Matched. It aims to help companies where the authors conduct research so that the data owned by the company becomes more optimal or better to do the process of troubleshooting SMS transactions and telephone calls to be valid or can be proven.

\section{RESEARCH METHODOLOGY}

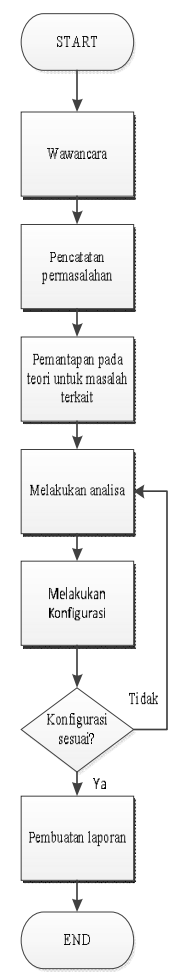

Figure 4:Research Method Flow Diagram

The position of the monitoring system that is running at the place where the author conducts research.

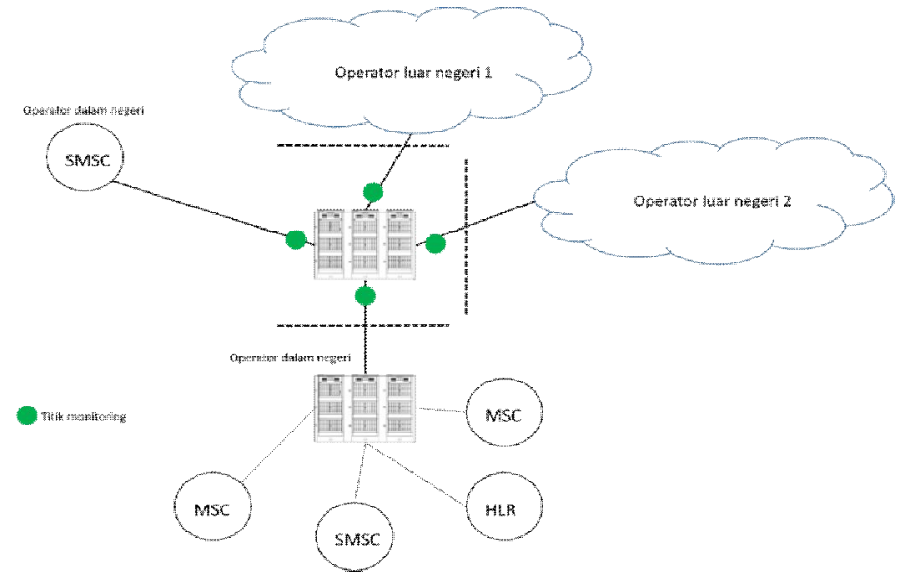

Figure 5: Ongoing Monitoring System Topology (Source

Processed, 2018)

The monitoring position of the author is in the middle which is most likely not directly connected to the SMS communication rates (SMCS, MSC, HLR, VLR, etc.)[5]. Where the purpose is the author's monitoring position only in the outgoing transaction path on the STP with a green dot.

At the position of the current monitoring point, the author can find out the transactions that will pass overseas or domestically. As a simulation if incoming messages from domestic operators through MSC, logically MSC will forward the SMS to the SMSC after the meal SMSC will be 
Aji Bagus Pambudi et al., International Journal of Emerging Trends in Engineering Research, 8(9), September 2020, $5832-5837$

forwarded to the HLR / VLR abroad to ensure the address and routing to reach the destination number. It can be seen in the picture that the transaction path will pass on the STP monitoring the author, the transaction departs and vice versa. In monitoring the SMS network at the provider where the author conducts research there is often incompleteness in the Call Detailed Record. This happens because MSU is from addressing SMS with different paths so that later for the monitoring process it will be difficult to ensure that the message arrives or not to the recipient, and for transaction based billing processes will be hampered because the data is incomplete[6].

In addition, the problem occurs if the data that is owned is less valid is to process the billing between telecommunications service providers. The billing process is broadly divided into two, namely MSU Based and Transaction Based. For billing on MSU Based, the calculation of costs is carried out per MSU passing on the telecommunication service provider device. Or it can be seen in table 1 in the "DR Status" column that indicates MSU from the SMS transaction.

Table 1:Status Monitoring Snapshot for MSU Based (1) (Source Processed, 2018)

\begin{tabular}{lll}
\hline Matching Id & DR Status & Way \\
\hline 30030 & Not matched $M S U$ & Incoming \\
30000 & Timer & Outgoing \\
\hline
\end{tabular}

Furthermore, for billing problems based on MSU Based can be seen in Table 2 below:

Table 2:Status Monitoring Snapshot for MSU Based (2) (Source Processed, 2018)

\begin{tabular}{|c|c|c|c|}
\hline $\begin{array}{l}\text { Matching } \\
\text { Id }\end{array}$ & Link type & DR Status & Way \\
\hline 30030 & $\begin{array}{l}\text { Intermediate } \\
\text { LSL }\end{array}$ & $\begin{array}{l}\text { Not matched } \\
M S U\end{array}$ & Incoming \\
\hline 30000 & $\begin{array}{l}\text { Intermediate } \\
\text { LSL }\end{array}$ & Timer & Outgoing \\
\hline
\end{tabular}

If the billing process is based on Transaction Based, the data cannot be used because Transaction Based must be based on one transaction in the monitoring. When referring to table 3 is to see how the Billing Transaction Based process.

Table 3:Transaction Status in Monitoring Application (Source Processed, 2018)

\begin{tabular}{|c|c|c|c|c|c|}
\hline $\begin{array}{l}\text { DP } \\
\text { C }\end{array}$ & $\begin{array}{l}\mathbf{O} \\
\mathbf{P C}\end{array}$ & $\begin{array}{l}\text { Li } \\
\text { nk }\end{array}$ & $\begin{array}{l}\text { Matching } \\
\text { Id }\end{array}$ & Protocol & $\begin{array}{l}\text { DR } \\
\text { Status }\end{array}$ \\
\hline - & - & - & 31006 & $\begin{array}{l}\text { MAP V3 layer } \\
\text { application }\end{array}$ & $\begin{array}{l}\text { OK (no } \\
\text { problem) }\end{array}$ \\
\hline
\end{tabular}

In table 3 if the author opens the contents of the "DR Status" it will appear as follows:
Table 4: Fill Transaction on OK (No Problem) Status (Source Processed, 2018)

\begin{tabular}{lllllr}
$\begin{array}{l}\text { Rec } \\
\text { No }\end{array}$ & Link & $\begin{array}{l}\text { Dest } \\
\text { Net Elem }\end{array}$ & $\begin{array}{l}\text { Orig } \\
\text { Net } \\
\text { Elem }\end{array}$ & Application & \\
\hline & & & BEGIN, & Op=MT \\
& & & & Forward & SM, \\
1 & - & - & - & IMSI=51010124103139 \\
& & & & 7, & Msg=SMS \\
& & & & DELIVER & \\
2 & - & - & & END, Return Result \\
\hline
\end{tabular}

Based on table 4, Billing is viewed from the Detailed Record status "OK (No Problem)" where in that status there is an MSU that is already in a group so that it creates one transaction, can be seen in table 4 above.

The matching process referred to by the author is equivalent to an SMS SS7 parameter based on the transaction ID. Transaction ID will be the same as the message send and the response message, so the writer does match or can also be referred to as connecting transactions of the same type.

For example the purpose of the Matching process can be seen in the table below:

Table 5: Example of Matching Process (Source Processed, 2018)

\begin{tabular}{lll}
\hline DR Status & OTID & DTID \\
\hline BEGIN & \$FFFFFFF & \$0D512C3A \\
\hline END & \$0D512C3A & \$FFFFFFFF \\
\hline
\end{tabular}

It can be seen that the Matching process is equalizing from the OTID and DTID, that if the same data is the same transaction.

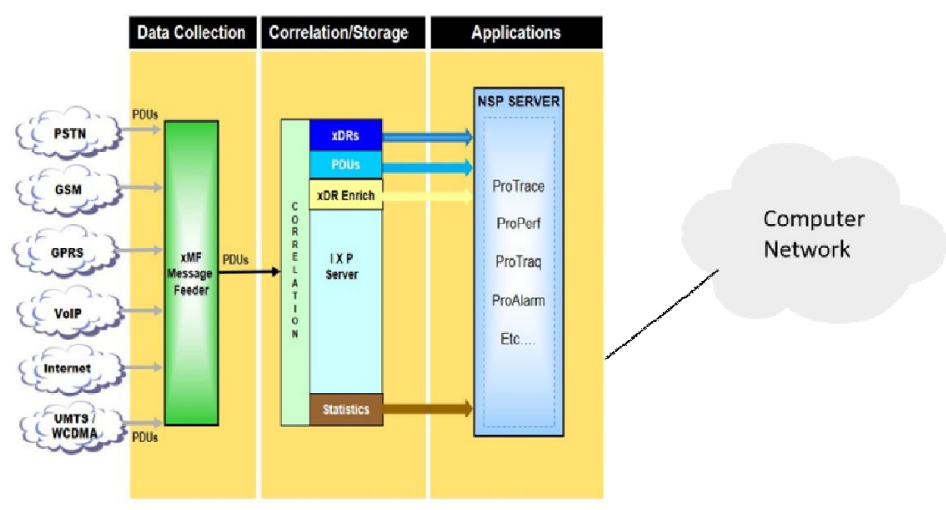

Figure 6: IAS Functional Components (IAS 9.0.3, 2014)

The following are the 3 main functional components of IAS:

- Data Collection

- IMF - Integrated Message Feeder

To capture SS7 traffic 
Aji Bagus Pambudi et al., International Journal of Emerging Trends in Engineering Research, 8(9), September 2020, $5832-5837$

- $\quad$ PMF - Probed Message Feeder

To capture IP traffic

- Correlation Data correlation and Storage

○ IXP Subsystem (integrated xDR Processor)

The process of connecting MSU which is part of the same signaling transaction to form an $\mathrm{xDR}$.

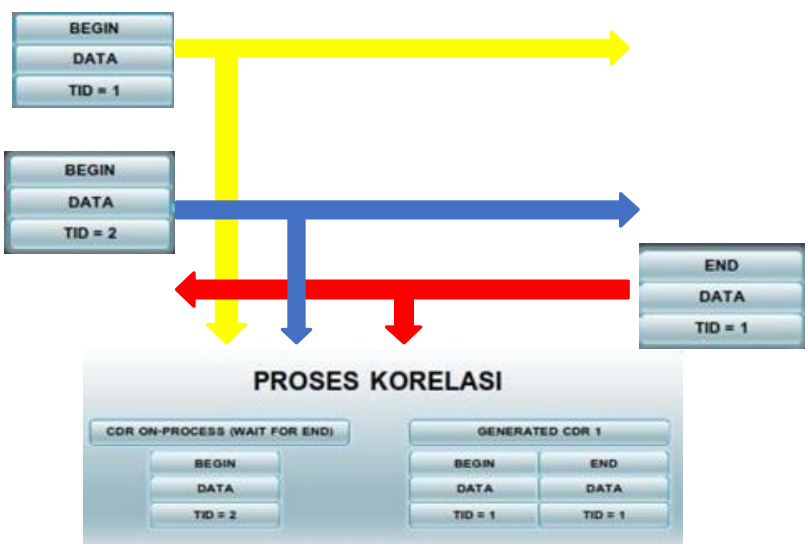

Figure 7: MSU Matching Process (IAS 9.0.3, 2014)

Functions generally do the Matching of data sent by data collection devices (IMF / PMF) then save it in the database in the form of xDR (Call / Transaction Detailed Record). In the above Matching process the TID is very influential. At TID = 1 it is perfectly matched, as much as TID $=2$ is still waiting for the END status to have TID $=2$.

\section{RESULT AND DISCUSSION}

3.1 Flowchart of the Matching search process on the OC-PIC
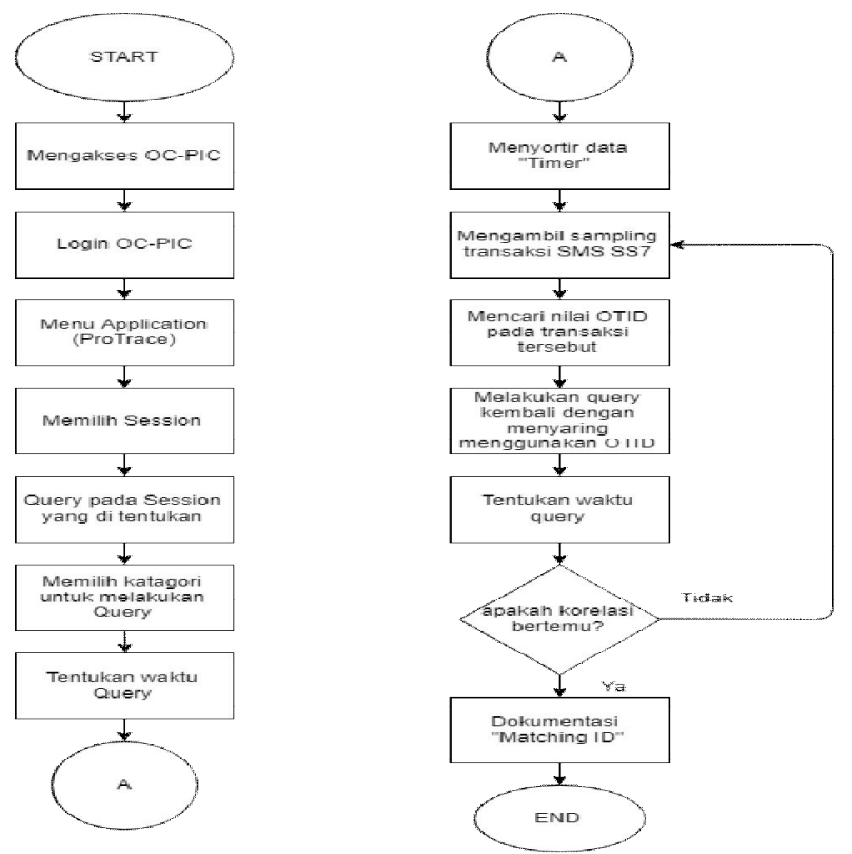

Figure 8: Matching process Flowchart

\subsection{Configuration Process on OC-PIC}

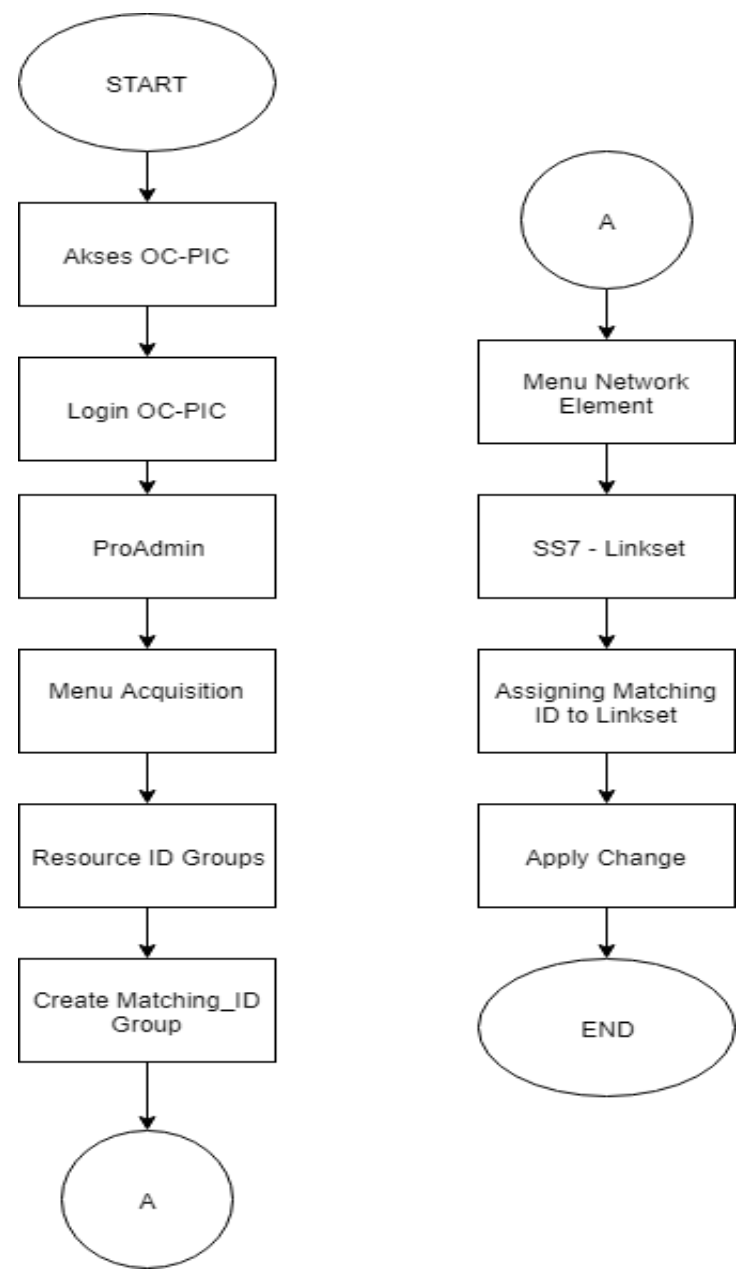

Figure 9:Configuration Process on OC-PIC

\subsection{Result of SMS SS7 Transaction after do the Configuration}

The following is a graph before the author does the matching and configuration process.

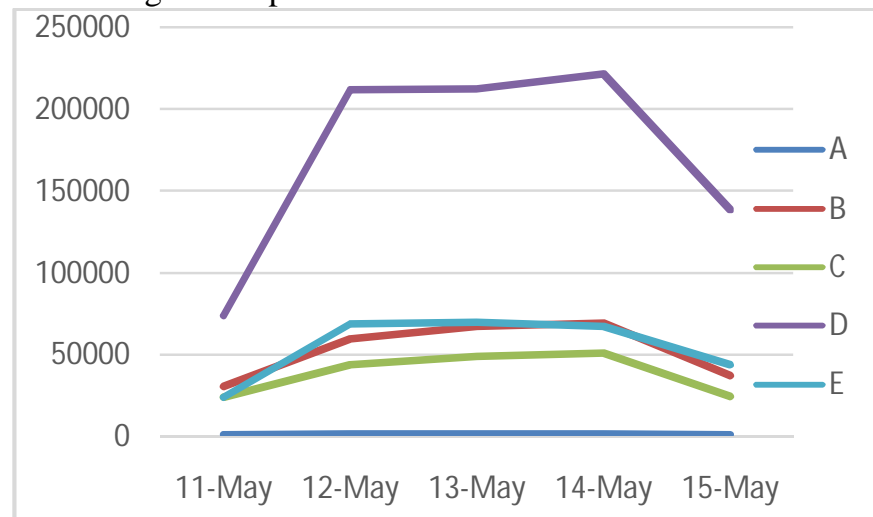

Figure 10:Status Chart "OK" Before being given an Action (Source Processed, 2018) 
Aji Bagus Pambudi et al., International Journal of Emerging Trends in Engineering Research, 8(9), September 2020, $5832-5837$

Seen in the graph in Figure 9, it is decreasing, the writer takes data for five days from May 112018 - May 15 with the reason the writer wants to get data that is stable for the author and can be used as a reference of the desired transaction status. In game 9 , it is claimed that transactions with "OK" status experience problems. The "OK" status that decreases will affect the transaction whose status "Not Matched" will increase, the following is a graph of the "Not Matched" status.

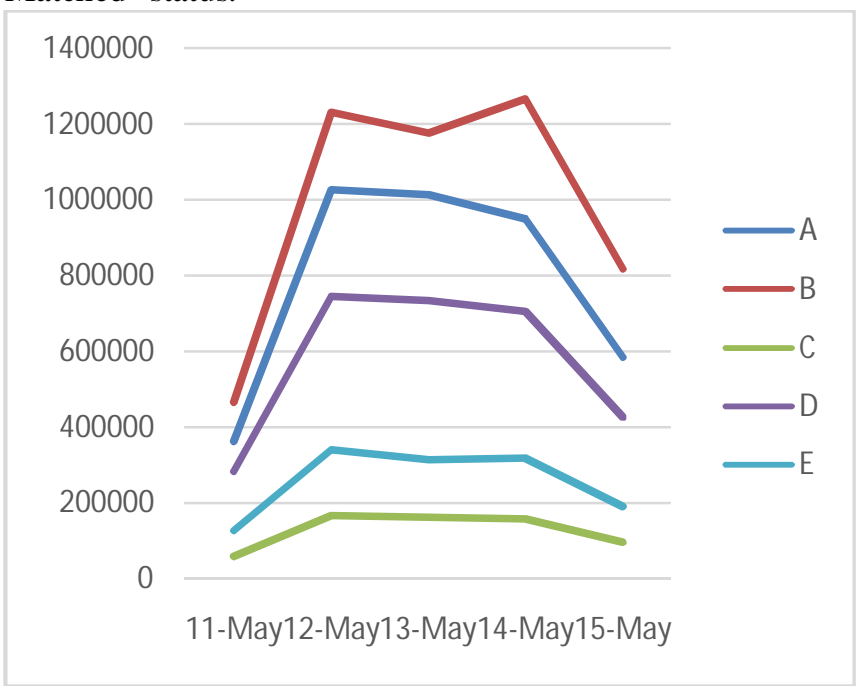

Figure 11:"Not Matched" Status Graph Before being Action (Source Processed, 2018)

Seen in Figure 10 the status chart "Not Matched" shows a high increase if the author looks at the number of transactions per-link. However, it can be seen on May 15, 2018 that the graph has decreased, because on the same date the author has carried out an execution to configure based on the link that the author found during the Matching process. The following will display the graph after the author has configured.

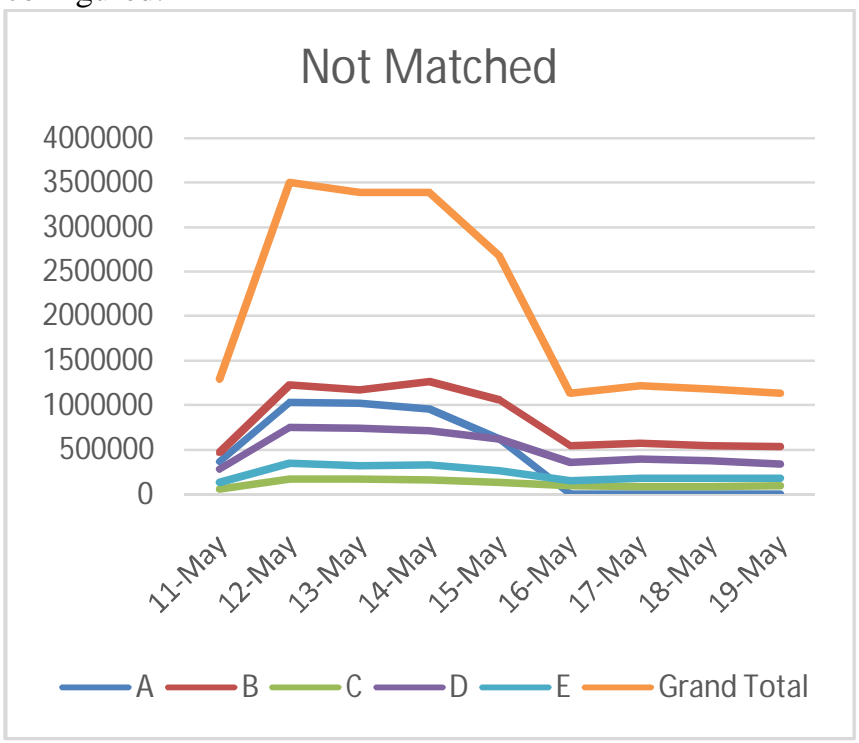

Figure 12: Graph "Not Matched" After being given an Action (Source Processed, 2018)
By decreasing the value of the status "Not matched" which can be seen in figure $11 \mathrm{can}$ be ascertained that the graph of the status OK after the author has configured it will also increase, here is a graphic image of the OK status that the previous configuration author.

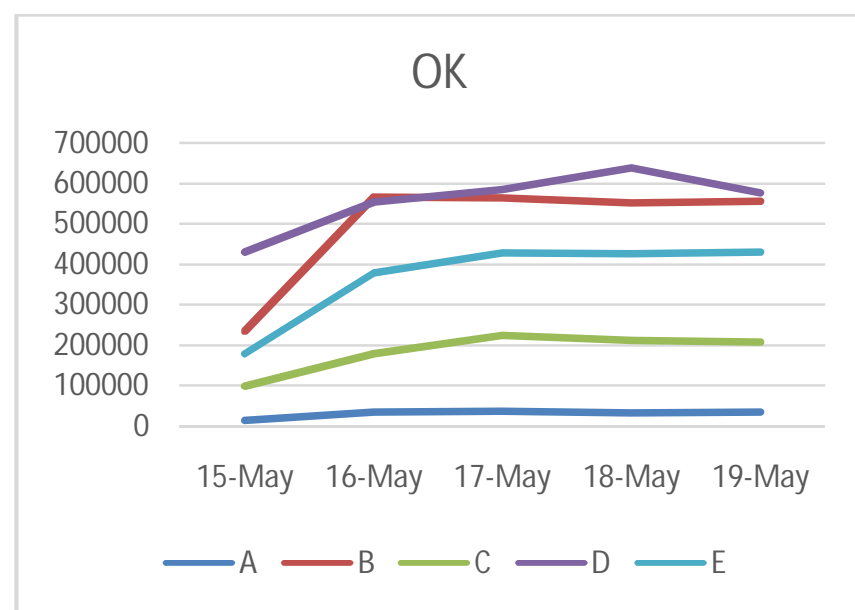

Figure 13:Graph "OK" After being given an Action (Source Processed, 2018)

We can see in figure 12 graph experiencing from May 15 , 2018 because the following date is where the author takes the configuration action. The reason the writer takes the next five days after the author has configured is to ensure a stable value in a transaction. It is seen that the value has stabilized starting on May 17, 2018, two days after the author has configured.

In Figures 13 and 14 below, the author combines the data that the author takes from May 11, 2018 - May 19, 2018, shown in the picture that the graph changes on May 15, 2018 because the date is where the author executes the configuration of the results that the author can Matching data.

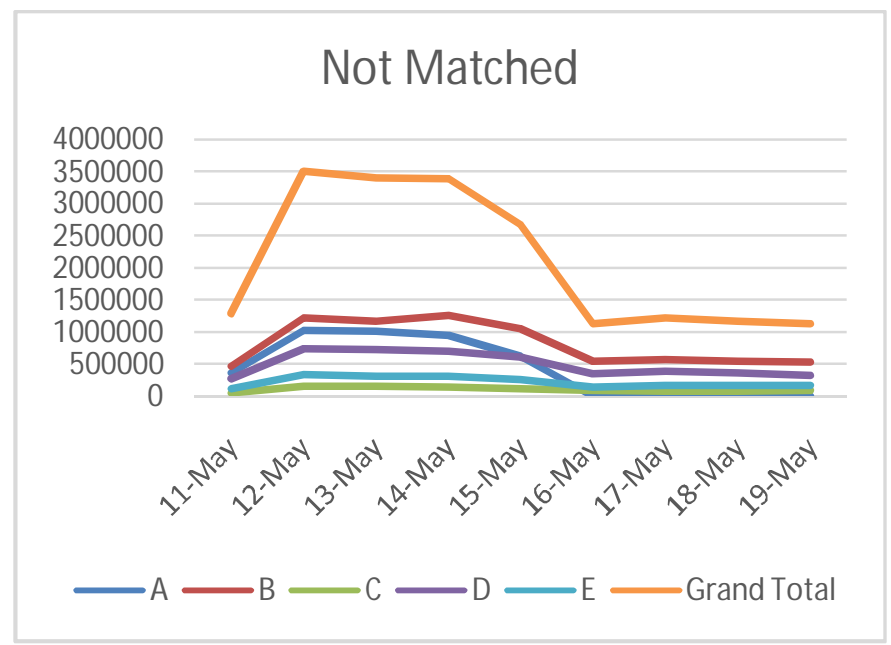

Figure 14:Overall Chart "Not Matched" (Configuration Date 15 May 2018) (Source Processed, 2018) 
Aji Bagus Pambudi et al., International Journal of Emerging Trends in Engineering Research, 8(9), September 2020, 5832 - 5837

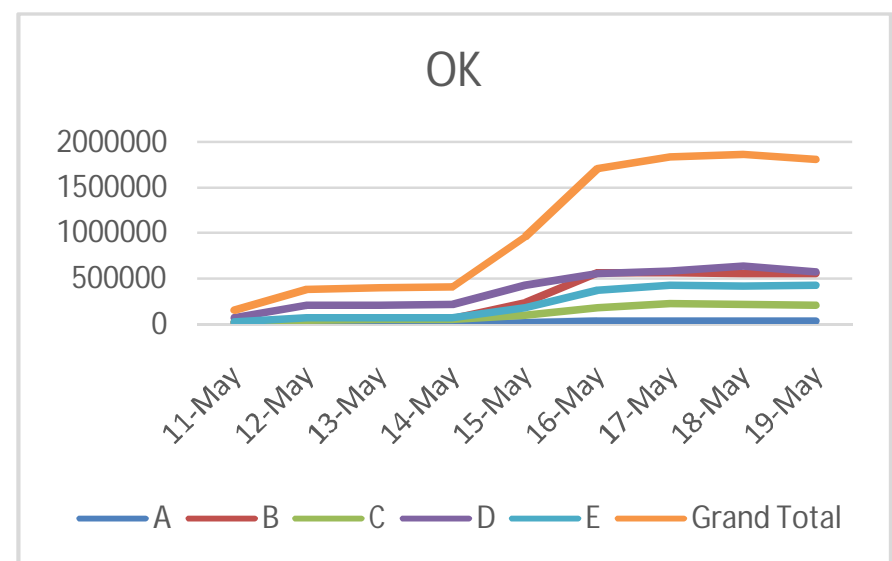

Figure 15:"OK" Overall Chart (Configuration Date 15 May 2018)

(Processed Resources, 2018)

\section{CONCLUSION}

Based on research that has been made and implemented in accordance with the subject matter, it can be concluded as follows:

1. Transaction ID (OTID / DTID) is the main parameter in the matching process

2. Matching ID is very influential in the matching process as a scope for MSU's that passes the link that we monitor

3. Changes to the appropriate Matching ID Configuration can improve the Call Data Record Validity in OC - PIC monitoring systems

SS7 SMS Process Roaming is an SMS message sent from a wireless network operator in one country to a wireless network operator in another country with the same topology as the local SS7 SMS.

\section{REFERENCES}

[1] A. D. M. Africa, F. X. Asuncion, J. L. L. Tiberio, R. Miguel and F. A. Munchua. Global Positioning System Using Mobile Phones: Three-Dimensional Positioning. International Journal of Emerging Trends in Engineering Research, 8 (2), pp. 295-299, 2020.

[2] V. Marwaha, H. S. Saini,\& D. Arora, A J-shaped Element Planar Inverted-F MIMO Antenna for 4G/5G Communication, International Journal of Emerging Trends in Engineering Research, 8 (2), 602-605, 2020.

[3] Geekzone, The Short Message Service. 2010.

[4] S. Faraz, Analysis of International Numbers of a Cell Phone. Department of Computer Science, Bisalpur: Shafi Dgree College, 2012.

[5] C. Laboue, Content of SS7 MAP SM Tdr. Morrisville: Tekelec, 2009

[6] L. Dryburgh\& J. Hewett,Signalling System No. 7 (SS7/C7): Protocol, Architecture, and Service. Indianapolis: Cisco Press, 2005 